\title{
Computerized Assessment of Wheezing in Children With Respiratory Syncytial Virus Bronchiolitis Before and After Hypertonic Saline Nebulization
}

\author{
Tina E Faber MD, Arvid WA Kamps MD PhD, Machtelt H Sjoerdsma MD, \\ Stephanie Vermeulen MD, Nic JGM Veeger PhD, and Louis J Bont MD PhD
}

\begin{abstract}
BACKGROUND: Studies suggest an effect of nebulized hypertonic saline solution on air-flow limitation in subjects with respiratory syncytial virus (RSV) bronchiolitis, but results are based on subjective scores of clinical severity and are not clear. In this observational study, we used a noninvasive computerized tool to quantify wheezing before and after nebulization with hypertonic saline in children admitted for RSV infection. METHODS: Twenty-seven children $(\leq 24$ months old) admitted to the pediatric ward of the Medical Center Leeuwarden with polymerase chain reaction-confirmed RSV bronchiolitis were included. Subjects were simultaneously assessed both clinically and by computerized acoustic monitoring before and 15 min after treatment with nebulized hypertonic saline solution. RESULTS: Clinical assessment, defined by the Respiratory Distress Assessment Instrument score, did not change after nebulization $(n=27,5.0$ vs $4.7, P=.17)$. Computerized acoustic monitoring showed no improvement in wheezing $(n=27,3.4 \%$ vs $2.0 \%$, $P=.05)$ or inspiration/expiration ratio $(0.85$ vs $0.85, P=.93)$ after nebulization. CONCLUSIONS: Hypertonic saline nebulization does not improve air flow, as assessed by both clinical and computerized acoustic scores, in children admitted for RSV. Key words: RSV; bronchiolitis; hypertonic saline; digital acoustic monitoring; nebulization; wheeze. [Respir Care 2015;60(9):1252-1256. () 2015 Daedalus Enterprises]
\end{abstract}

\section{Introduction}

Treatment of respiratory syncytial virus (RSV) bronchiolitis, a disease that affects almost all children by the time they reach their second year of life, remains supportive.

Drs Faber, Kamps, Sjoerdsma, and Vermeulen are affiliated with the Department of Pediatrics, and Dr Veeger is affiliated with the Department of Clinical Epidemiology, MCL Academy, Medical Center Leeuwarden, Leeuwarden, The Netherlands. Dr Bont is affiliated with the Department of Pediatrics, Wilhelmina Children's Hospital, University Medical Center Utrecht, Utrecht, The Netherlands.

This study was supported by the Science Foundation of the Medical Staff of the Medical Center Leeuwarden. Funding was used to purchase the PulmoTrack. The authors disclosed no conflicts of interest.

Correspondence: Tina E Faber MD, Department of Pediatrics, Medical Center Leeuwarden, Henri Dunantweg 2, 8934 AD Leeuwarden, The Netherlands. E-mail: tina.faber@znb.nl.

DOI: $10.4187 /$ respcare. 03754
Approximately $40-50 \%$ of infected infants develop infection of the lower respiratory tract, leading to hospitalization in $1-2 \%$ of cases. ${ }^{1}$ Numerous therapies have been tried, such as bronchodilators, nebulized adrenaline, inhaled or systemic steroids, cromoglycate, immunoglobulins, and antiviral treatment, but meta-analyses have failed to show evidence of effect. ${ }^{2-5}$ Several studies suggest a beneficial effect from nebulization with hypertonic saline solution on clinical severity scores, but results are not entirely clear. ${ }^{2,6,7}$ The main rationale for hypertonic saline treatment in bronchiolitis is rehydration of the airway surface liquid, leading to increased airway surface thickness, decreased epithelial edema, improved mucus rheologic properties such as elasticity and viscosity, and acceleration of mucus transport rates, thus increasing mucus clearance. ${ }^{8}$ Due to possible beneficial effects, lack of adverse effects, and limited cost, pediatricians often use this mode of therapy on a trial-and-error basis.

The PulmoTrack (KarmelSonix, Haifa, Israel), a respiratory acoustic monitor, is a validated tool to digitally 
quantify lung sounds such as wheezing and cough. ${ }^{9} \mathrm{Com}-$ puterized wheeze detection has been shown to be feasible in young children. ${ }^{10}$ In healthy adult volunteers, specificity and sensitivity for detection of cough events are high (94\% and 96\%, respectively). ${ }^{11}$ In children with asthma, this method has been used to provide quantitative information about wheezing and efficacy of treatment, and it correlates well with conventional indices of bronchial obstruction such as FEV ${ }_{1}$ and FVC. ${ }^{12}$ In the pediatric ICU, the PulmoTrack was significantly more sensitive than physicians in detecting wheezing. ${ }^{13} \mathrm{Re}-$ spirosonography was successfully used in children with RSV bronchiolitis to evaluate wheeze patterns ${ }^{14}$ and to assess treatment efficacy of nebulized salbutamol and epinephrine..$^{9,15}$ The authors concluded that it provided a noninvasive method for objective clinical assessment of young children with wheezing.

There are no objective diagnostics assessing the direct effects of any treatment on air-flow limitation in children with RSV bronchiolitis. Results of previous studies are unclear and based on subjective measurements such as clinical severity scores. We therefore performed an observational study and used the PulmoTrack to quantify airway obstruction in children admitted for RSV bronchiolitis before and after nebulization with hypertonic saline solution.

\section{Methods}

The study protocol was approved by the institutional review board at the Medical Center Leeuwarden in The Netherlands (TPO787a). In this observational study, infants $\leq 24$ months old admitted to the pediatric ward at the Medical Center Leeuwarden with a polymerase chain reaction-confirmed diagnosis of RSV bronchiolitis were eligible to enroll. Symptoms of bronchiolitis were coughing, wheezing, rales, use of accessory muscles, and/or nasal flaring. ${ }^{16}$ Exclusion criteria included preexisting lung disease such as asthma, cystic fibrosis, or laryngomalacia; use of bronchodilators or corticosteroids, and severe illness requiring mechanical ventilation. The following subject characteristics were recorded: sex, gestational age, age at admission, antibiotic use before admission, temperature and oxygen saturation at time of admission, and comorbidity (non-respiratory).

After parents agreed to participate and gave written informed consent, the PulmoTrack was put in place. The study was performed on the day of admission, and all included subjects received hypertonic saline administrated via jet nebulizers with continuous flow of $100 \%$ oxygen. Similar to previous studies, a concentration of $3 \%$ was used with a 4-mL volume. ${ }^{9,17-20}$ The PulmoTrack system consists of two acoustic sensors attached to the skin over the trachea and chest with disposable insulating adhesive

\section{QUICK LOOK}

\section{Current knowledge}

Treatment of respiratory syncytial virus (RSV) bronchiolitis remains largely supportive. Limited data suggest a potential beneficial effect from nebulization of hypertonic saline solution on clinical severity scores with unclear mechanisms. The rationale for hypertonic saline treatment is rehydration of the airway surface liquid, decreased epithelial edema, improved mucus rheologic properties, and enhanced mucus clearance.

\section{What this paper contributes to our knowledge}

Both clinical assessment and acoustic monitoring demonstrated that hypertonic saline nebulization had no short-term effect on wheezing, breathing frequency, or inspiration/expiration ratios in children admitted for RSV. Cough episodes increased after nebulization, but the clinical implications of this result are unclear and could be secondary to airway irritation.

pads, a pneumograph belt sensor to document breathing activity, and an ambient microphone to filter environmental noises, all attached to a laptop. Wheezing was detected using the KarmelSonix software with advanced algorithms that apply strict criteria to determine the presence of wheezing. Wheezing, as defined by computerized respiratory sound analysis guidelines, is characterized by periodic waveforms with a dominant frequency of $>100 \mathrm{~Hz}$ with a duration of $\geq 100 \mathrm{~ms}^{21}$ The wheeze rate (percent of time wheezing/total breath time), breathing frequency, inspiration/expiration (I:E) ratio, and cough events (frequency content between 50 and $3,000 \mathrm{~Hz}$ ) were measured via the PulmoTrack in all subjects for a period of $5 \mathrm{~min}$ both before and $15 \mathrm{~min}$ after single nebulization with $4 \mathrm{~mL}$ of hypertonic $(3 \%)$ saline solution. Considering the duration of nebulization of $\sim 10 \mathrm{~min}$, actual assessment was performed at 25-35 min after start of nebulization. Simultaneously during both 5-min intervals of PulmoTrack recording, disease severity was clinically assessed using the modified Respiratory Distress Assessment Instrument score once before and once $15 \mathrm{~min}$ after nebulization. The Respiratory Distress Assessment Instrument score has a range of $0-12$ and evaluates breathing frequency, use of accessory muscles, color, and auscultation. ${ }^{22,23}$ Heart rate and breathing frequency before and after nebulization were also noted. Care was taken to ensure that all infants were relatively settled and not crying during the assessment. According to standard care in our hospital for patients with bronchiolitis, laboratory tests and $\mathrm{x}$-rays were not routinely performed. 
In the statistical analysis, the Wilcoxon signed-rank test for paired samples was used. $P<.05$ was considered statistically significant.

\section{Results}

A total of 30 infants with bronchiolitis were eligible to enroll in the study during the winter season of 2012-2013. Three subjects were excluded for being RSV-negative. The average age at time of admission was 4.9 months. All but one child were younger than 12 months. There was a larger percentage of male infants $(67 \%, n=18)$, and most were term babies $(85 \%, n=23)$. Almost half of the infants presented with fever and needed oxygen therapy (Table 1).

Clinical assessment before and after nebulization with hypertonic saline showed no improvement in total Respiratory Distress Assessment Instrument scores. Analysis of the individual parameters showed slight improvement in accessory muscle use, but no improvement in breathing frequency, color, or auscultation. Heart rate did not differ

Table 1. Subject Characteristics

\begin{tabular}{lc}
\hline \multicolumn{1}{c}{ Clinical and Demographic Data } & Values \\
\hline Age at admission, mean \pm SD mo & $4.9 \pm 4.8$ \\
Males, $n(\%)$ & $18(67)$ \\
Gestational age $<37 \mathrm{wk}, n(\%)$ & $4(15)$ \\
Temperature $>38.5^{\circ} \mathrm{C}$ at admission, $n(\%)$ & $13(48)$ \\
Oxygen saturation $<92 \%$ at admission, $n(\%)$ & $11(41)$ \\
Comorbidity (non-pulmonary), $n(\%)$ & $2(7)$ \\
Antibiotics prescribed preadmission, $n(\%)$ & $5(19)$ \\
& \\
\hline
\end{tabular}

after nebulization. Digital acoustic monitoring showed large individual differences in efficacy of nebulization for wheezing; 9 of $27(33 \%)$ subjects showed a clear decrease in wheezing, and 5 of $27(18 \%)$ subjects showed a clear increase in wheezing. Overall, no improvement in wheezing, breathing frequency, or I:E ratio was found after nebulization. Percentage of cough increased after nebulization. No other side effects occurred. In a subgroup analysis of subjects with more severe disease (Respiratory Distress Assessment Instrument score $\geq 5, n=15$ ), results were comparable (Table 2).

\section{Discussion}

This is the first study to use computerized acoustic monitoring to assess the acute effect of hypertonic saline nebulization in children with RSV bronchiolitis. Clinical assessment by Respiratory Distress Assessment Instrument scores showed no effect of nebulization. Results were confirmed by digital acoustic monitoring showing that hypertonic saline nebulization had no short-term effect on wheezing, breathing frequency, or I:E ratios in children admitted for RSV. The number of cough episodes increased after nebulization, but the clinical implications of this result are not clear. Increased cough reflex is due either to direct stimulation of cough receptors by hypertonic saline or to increased mucus clearance. Increased cough may cause increased dyspnea in some subjects, whereas others may benefit from loosening of mucus plugs. ${ }^{8,20}$

Previous studies have used respirosonography to assess treatment modalities (other than hypertonic saline) in

Table 2. Clinical and Quantified Effects of Hypertonic Saline Nebulization in Respiratory Syncytial Virus Bronchiolitis

\begin{tabular}{|c|c|c|c|}
\hline & $\begin{array}{l}\text { Pre-Nebulization } \\
\quad(N=27)\end{array}$ & $\begin{array}{l}\text { Post-Nebulization } \\
\quad(N=27)\end{array}$ & $P^{*}$ \\
\hline \multicolumn{4}{|c|}{ Respiratory Distress Assessment Instrument scores } \\
\hline Total No. & $5.00 \pm 1.59$ & $4.74 \pm 1.61$ & .17 \\
\hline Breathing frequency & $0.70 \pm 0.61$ & $0.52 \pm 0.70$ & .23 \\
\hline Accessory Muscle & $1.67 \pm 0.88$ & $1.44 \pm 0.85$ & .01 \\
\hline Color & $0.81 \pm 1.00$ & $0.81 \pm 1.00$ & .99 \\
\hline Auscultation & $1.85 \pm 0.36$ & $1.93 \pm 0.27$ & .16 \\
\hline Heart rate, beats/min & $147 \pm 14.0$ & $145 \pm 12.9$ & .53 \\
\hline Breathing frequency, breaths/min & $50 \pm 11.0$ & $51 \pm 12.8$ & .61 \\
\hline \multicolumn{4}{|l|}{ Digital acoustic monitoring $\dagger$} \\
\hline Percentage wheezing & $3.4 \pm 3.84$ & $2.0 \pm 2.74$ & .05 \\
\hline I:E ratio & $0.85 \pm 0.15$ & $0.85 \pm 0.18$ & .93 \\
\hline No. of cough episodes & $1.44 \pm 2.42$ & $2.63 \pm 3.36$ & .03 \\
\hline \multicolumn{4}{|c|}{$\begin{array}{l}\text { Values are presented as mean } \pm \mathrm{SD} \text {. } \\
\text { * Wilcoxon signed-rank test. } \\
\dagger \text { Values are presented as mean } \pm \mathrm{SD} \text { during a 5-min interval. } \\
\mathrm{I}: \mathrm{E}=\text { inspiration/expiration }\end{array}$} \\
\hline
\end{tabular}




\section{Wheezing Before and After Hypertonic Saline Nebulization}

children with bronchiolitis. In a study including 16 infants with bronchiolitis, 7 infants showed a decrease in proportion of wheezing (time spent wheezing/total respiratory time) after nebulization with salbutamol. ${ }^{9}$ Another study including 27 children with RSV bronchiolitis found no significant change in objective quantification of wheezing and crackles $10 \mathrm{~min}$ after nebulization with epinephrine and albuterol. ${ }^{15}$ Both studies concluded that computerized lung sound analysis is feasible in young infants with bronchiolitis and that it provides a noninvasive, quantitative measure of wheezing.

Regarding previous studies that used clinical scores to assess effects of hypertonic saline nebulization, a Cochrane review analyzed 7 double-blind parallel-group randomized controlled trials including 581 infants with bronchiolitis. Combined results showed an $\sim 1$-day reduction in hospital stay and an improvement in clinical severity scores in subjects treated with nebulized hypertonic saline compared with normal saline. ${ }^{6}$ Two of the included studies were performed in the emergency department and assessed shortterm effects, ${ }^{17,24}$ as in our study. In one study, clinical scores improved, whereas in the other study, they did not. In both studies, hypertonic saline was combined with either salbutamol or epinephrine. Considering heterogeneity in effect sizes and combined treatment modalities in all studies, the effect of monotherapy with nebulized hypertonic saline remains unclear. The results from our study indicate, by quantitative assessment, that monotherapy with nebulized hypertonic saline has no short-term effects. This is in accordance with a recent study that found no clinical improvement in infants with bronchiolitis and respiratory distress in the emergency department after administration of a single dose of nebulized hypertonic saline. ${ }^{7}$

Although clinical severity scores are generally accepted as relatively objective measurements to assess severity of illness, the greatest strength of this study is the computerized acoustic monitor, which allows objective assessment of treatment efficacy. Limitations of this study lie in the observational design and small sample size. Furthermore, the aim of our study was to evaluate short-term effects $\sim 30 \mathrm{~min}$ after start of nebulization, but repeat assessments were not performed. Therapeutic effects $2 \mathrm{~h}$ post-nebulization cannot be ruled out, although a previous study found no difference in clinical outcome after 120 min. ${ }^{24}$ Future studies should use digital acoustic monitoring to assess therapeutic effects $2 \mathrm{~h}$ post-nebulization or effects of multiple nebulizations. Studies in ventilated infants could include specific measurements of airway resistance, oxygenation, and ventilation index..$^{25}$ Caution is also warranted in extrapolation of data to out-patients and those with severe bronchiolitis requiring ventilation, as these patients were excluded from the study.

\section{Conclusions}

Computerized acoustic monitoring shows that monotherapy with nebulized hypertonic saline has no short-term effect on wheezing, breathing frequency, or I:E ratios in children admitted for RSV. The PulmoTrack is a useful noninvasive tool to quantify airway obstruction in young children with RSV bronchiolitis and enables objective evaluation of treatment modalities in both clinical and experimental settings.

\section{REFERENCES}

1. Behrendt CE, Decker MD, Burch DJ, Watson PH. International variation in the management of infants hospitalized with respiratory syncytial virus. International RSV Study Group. Eur J Pediatr 1998; 157(3):215-220.

2. Lenney W, Boner AL, Bont L, Bush A, Carlsen KH, Eber E, et al. Medicines used in respiratory diseases only seen in children. Eur Respir J 2009;34(3):531-551.

3. Gadomski AM, Scribani MB. Bronchodilators for bronchiolitis. Cochrane Database Syst Rev 2014;6:CD001266.

4. Fernandes RM, Bialy LM, Vandermeer B, Tjosvold L, Plint AC, Patel H, et al. Glucocorticoids for acute viral bronchiolitis in infants and young children. Cochrane Database Syst Rev 2013;6:CD004878.

5. Plint AC, Johnson DW, Patel H, Wiebe N, Correll R, Brant R, et al. Epinephrine and dexamethasone in children with bronchiolitis. N Engl J Med 2009;360(20):2079-2089.

6. Zhang L, Mendoza-Sassi RA, Wainwright C, Klassen TP. Nebulised hypertonic saline solution for acute bronchiolitis in infants. Cochrane Database Syst Rev 2013;7:CD006458.

7. Florin TA, Shaw KN, Kittick M, Yakscoe S, Zorc JJ. Nebulized hypertonic saline for bronchiolitis in the emergency department: a randomized clinical trial. JAMA Pediatr 2014;168(7):664-670.

8. Mandelberg A, Amirav I. Hypertonic saline or high volume normal saline for viral bronchiolitis: mechanisms and rationale. Pediatr Pulmonol 2010;45(1):36-40.

9. Tal A, Sanchez I, Pasterkamp H. Respirosonography in infants with acute bronchiolitis. Am J Dis Child 1991;145(12):1405-1410.

10. Puder LC, Fischer HS, Wilitzki S, Usemann J, Godfrey S, Schmalisch G. Validation of computerized wheeze detection in young infants during the first months of life. BMC Pediatr 2014;14:257.

11. Vizel E, Yigla M, Goryachev Y, Dekel E, Felis F, Levi H, et al. Validation of an ambulatory cough detection and counting application using voluntary cough under different conditions. Cough 2010; $6: 3$.

12. Bentur L, Beck R, Shinawi M, Naveh T, Gavriely N. Wheeze monitoring for assessment of nocturnal asthma and response to therapy. Eur Respir J 2003;21(4):621-626.

13. Prodhan P, Dela Rosa RS, Shubina M, Haver KE, Matthews BD, Buck $S$, et al. Wheeze detection in the pediatric intensive care unit: comparison among physician, nurses, respiratory therapists, and a computerized respiratory sound monitor. Respir Care 2008;53(10): 1304-1309.

14. Sánchez I, Navarro H, Bertrand P, Alvarez C, Lisboa C. Acoustic analysis of wheezing in infants with acute bronchial obstruction. Rev Med Chil 2002;130(7):760-767.

15. Beck R, Elias N, Shoval S, Tov N, Talmon G, Godfrey S, Bentur L. Computerized acoustic assessment of treatment efficacy of nebulized 


\section{Wheezing Before and After Hypertonic Saline Nebulization}

epinephrine and albuterol in RSV bronchiolitis. BMC Pediatr 2007; $7: 22$.

16. Ralston SL, Lieberthal AS, Meissner HC, Alverson BK, Baley JE, Gadomski AM, et al. Clinical practice guideline: the diagnosis, management, and prevention of bronchiolitis. Pediatrics 2014;134(5): e1474-1502.

17. Anil AB, Anil M, Saglam AB, Cetin N, Bal A, Aksu N. High volume normal saline alone is as effective as nebulized salbutamol-normal saline, epinephrine-normal saline, and 3\% saline in mild bronchiolitis. Pediatr Pulmonol 2010;45(1):41-47.

18. Kuzik BA, Al-Qadhi SA, Kent S, Flavin MP, Hopman W, Hotte S, Gander S. Nebulized hypertonic saline in the treatment of viral bronchiolitis in infants. J Pediatr 2007;151(3):266.e1-270.e1.

19. Luo Z, Fu Z, Liu E, Xu X, Fu X, Peng D, et al. Nebulized hypertonic saline treatment in hospitalized children with moderate to severe viral bronchiolitis. Clin Microbiol Infect 2011;17(12):1829-1833.

20. Mandelberg A, Tal G, Witzling M, Someck E, Houri S, Balin A,
Priel IE. Nebulized 3\% hypertonic saline solution treatment in hospitalized infants with viral bronchiolitis. Chest 2003;123(2):481-487.

21. Sovijarvi ARA, Dalmasso F, Vanderschoot J, Malmberg LP, Righini G, Stoneman SAT. Definition of terms for application of respiratory sounds. Eur Respir Rev 2000;10(77):597-610.

22. Klassen TP, Sutcliffe T, Watters LK, Wells GA, Allen UD, Li MM. Dexamethasone in salbutamol-treated inpatients with acute bronchiolitis: a randomized, controlled trial. J Pediatr 1997;130(2):191-196.

23. Chan P, Goh A. Respiratory syncytial virus infection in young Malaysian children. Singapore Med J 1999;40(5):336-340.

24. Grewal S, Ali S, McConnell DW, Vandermeer B, Klassen TP. A randomized trial of nebulized $3 \%$ hypertonic saline with epinephrine in the treatment of acute bronchiolitis in the emergency department. Arch Pediatr Adolesc Med 2009;163(11):1007-1012.

25. Numa AH, Williams GD, Dakin CJ. The effect of nebulized epinephrine on respiratory mechanics and gas exchange in bronchiolitis. Am J Respir Crit Care Med 2001;164(1):86-91. 